\title{
GESTÃO POR COMPETÊNCIAS - SELEÇÃO DE PESSOAS POR COMPETÊNCIAS
}

\section{ARTIGO DE REVISÃO}

ÁVILA, Maria Zita de ${ }^{1}$

CASELLA, Maurício Leser ${ }^{2}$

ÁVILA, Maria Zita de. CASELLA, Maurício Leser. Gestão por competências Seleção de pessoas por competências. Revista Científica Multidisciplinar Núcleo do Conhecimento. Ano 04, Ed. 10, Vol. 07, pp. 133-146. Outubro de 2019. ISSN: 24480959, Link de

acesso: https://www.nucleodoconhecimento.com.br/administracao/selecao-depessoas

\section{RESUMO}

O presente estudo objetivou discorrer sobre a seleção de pessoas por competências, dentro de uma gestão por competências. Para alcançar o objetivo proposto utilizou-se como metodologia a pesquisa bibliográfica em livros, artigos e teses pertinentes ao tema em questão. Neste artigo, foi visto o que é a gestão por competências e o que está envolvido na seleção por competências, também, o nível de assertividade deste processo, as vantagens e desvantagens dele, e as contribuições deste método para a organização como um todo. Ao final do estudo, concluiu-se que a finalidade da seleção por competências é tornar o processo de seleção mais abrangente, buscando

1 Pós Graduação/ /Especialização em Contabilidade, Universidade Federal de Mato Grosso - UFMT / Instituto de Ciências Sociais; Pós Graduação / Gestão de Pessoas, Centro Universitário Leonardo da Vinci; Graduação: Ciências Contábeis, Universidade Federal de Mato Grosso - UFMT.

${ }^{2}$ Bacharel em Ciências Contábeis pela Pontifícia Universidade Católica/RS, pósgraduado em Gestão e Operações Logísticas pela UNIASSELVI. 
identificar não somente características pessoais e profissionais nos candidatos, mas também suas competências e a adequação das mesmas na atividade ofertada na organização, evitando assim falhas que são mais comuns em outros métodos de processo de seleção. Além disso, este tipo de seleção por competência contribuirá de forma positiva para que as estratégias organizacionais previamente definidas, sejam colocadas em prática e obtenham o sucesso almejado, pois neste tipo de método, as pessoas que farão parte da organização é que são o ponto principal a ser levado em conta e, até mesmo, ser visto como um diferencial de competitividade diante dos seus concorrentes.

Palavras-chave: Competências, gestão por competências, seleção por competências.

\section{INTRODUÇÃO}

Este artigo tem como tema "Gestão por competências: seleção de pessoas por competências", tendo em vista que as organizações estão observando a necessidade de se adequar a novos modelos de gestão. Embora os primeiros estudos de competências iniciaram-se em 1970, esse termo é muito utilizado nas empresas dos tempos modernos (FLEURY E FLEURY, 2004). Para Dutra (2004), agregar valor nas pessoas é uma contribuição importante para a gestão de conhecimentos da organização, além de auxiliar na manutenção das suas vantagens competitivas no tempo. Diante disso, a gestão por competências vem contribuir justamente para que as empresas encontrem e retenham os talentos. Partindo desta perspectiva é que o processo de seleção se tornou um ponto estratégico para as empresas, e este artigo aborda justamente a questão da seleção de talentos, mas do ponto de vista de uma seleção por competências, que pode contribuir tanto para as práticas organizacionais, quanto para o próprio profissional que venha a fazer parte da organização.

Embora muito ainda se utilize o processo de seleção dito como tradicional dentro das empresas, o qual é composto por diversas etapas, isso para que uma etapa possa compensar eventuais falhas de outras, surgiu no cenário organizacional uma nova forma de realizar a seleção de pessoas, e a esta, se deu o nome de seleção por competências. Sendo assim, para entender melhor esse novo processo, será definido 
neste artigo, o que se tem denominado por gestão de competências e o método de seleção por competências. O objetivo maior da seleção por competências é criar um perfil de competências para cada cargo dentro da organização, ou seja, elaborar um mapeamento de competências que façam parte das estratégias de competitividade e diferenciação no mercado de trabalho. (RABAGLIO, 2001).

Diante deste processo de seleção por competência é que surge o problema de pesquisa estudado neste artigo, ou seja, como o processo de Gestão por competência e a seleção por competência tem influenciado na gestão das organizações?

Com o propósito de responder à questão de pesquisa, tem-se como objetivo geral, identificar a relação da seleção por competências na gestão das organizações.

Para tanto, traçou-se os seguintes objetivos específicos: identificar a gestão por competências; explicar o conceito de competência; identificar a seleção por competências e identificar a relevância das competências na seleção de pessoas.

A escolha do tema justifica-se, pois, a seleção tem como objetivo minimizar os riscos do mau posicionamento de um colaborador dentro da organização e a seleção por competência, certamente suprirá está necessidade. Porque, um colaborador bem posicionado, ou na função certa, aumenta as chances de realizar um trabalho satisfatório, o que contribui grandemente para a organização.

Tendo a melhoria da organização em mente, a seleção por competências foi vista como sendo uma oportunidade de as empresas na parte de gestão de pessoas, atuarem de maneira mais integrada com as demais áreas da organização, além de efetuar a incorporação de papéis estratégicos, o que por sua vez, trará respostas rápidas para a organização, assim como um perfil mais dinâmico, tanto para os colaboradores, quanto para os gestores.

De fato, este método de seleção por competências é agregador de novas possibilidades dentro da organização, no entanto, é necessário que a cultura da empresa também vá de encontro as competências, o que muitas vezes significa mudança nos sistemas já incorporados, bem como uma inovação na prática de gerir 
as pessoas, na maneira de pensar e também de agir para com o colaborador da organização.

A metodologia utilizada neste estudo, foi a pesquisa bibliográfica em livros, artigos e teses que tratam a temática abordada.

\section{GESTÃO POR COMPETÊNCIAS}

Não se pode falar em gestão por competências, se a organização não pensar em um processo integral e estratégico, que abrange todos os subsistemas da gestão de pessoas. O recrutamento e a seleção, o treinamento e o desenvolvimento, a avaliação por desempenho, a remuneração por desempenho e ainda, questões sindicais.

À medida que estas, estiverem vinculadas a uma gestão voltada para resultados, que visam o alinhamento entre indivíduo e organização, terão como pontos fortes: a satisfação do colaborador e a excelência nos resultados de uma maneira integrada.

\subsection{CONCEPÇÕES E CARACTERÍSTICAS}

A busca por indivíduos capacitados não é recente, já na época em que se utilizava o princípio taylorista, havia a preocupação em treinar e capacitar os indivíduos para as tarefas, apesar da capacitação ser voltada apenas para os conhecimentos e habilidades técnicas relacionadas ao trabalho (RUAS, ANTONELLO E BOFF, 2005). Notadamente, nas últimas décadas vem sendo construído um novo conceito de gestão de pessoas, Fischer (2012), diz que o modelo de gestão de pessoas é a maneira pela qual a empresa se organiza para gerenciar e orientar o comportamento humano no trabalho.

Dutra (2011) afirma que a maneira pela qual as organizações de todo o mundo trabalham a gestão de pessoas, passa nos últimos anos por grandes transformações e essas transformações, se fizeram necessárias tendo em vista que os modelos tradicionais não atendem mais as necessidades e expectativas das empresas e das pessoas. Mas segundo o autor, para que este novo modelo tenha sucesso, é necessário que esse conceito de gestão por competências esteja abrangendo todas 
as áreas, ou seja, desde o recrutamento até a gestão de carreiras, avaliação por desempenho e remuneração.

Sobre isso, Leme (2005) menciona que a "Gestão por Competências é um projeto que deve partir da direção da empresa, mas precisa ser compartilhado por todos os colaboradores". O autor ainda relata, que devido à falta de preparação de muitos profissionais e/ou da crença de que o processo é complicado ou oneroso, algumas empresas implantam o modelo em apenas algumas funções, geralmente só em um ou poucos setores da empresa ou apenas em funções do nível da gerência para cima. Porém, não é possível afirmar, que se for realizado desta maneira, o processo não seja válido ou não traga resultado, mas sim que, se implantado desta forma é um processo incompleto, e por isso a organização poderá não obter todos os ganhos que o modelo oferece.

O mais agravante é que muitas organizações afirmam que seus funcionários são o ativo mais importante, no entanto suas práticas gerenciais contradizem essa afirmação, pois muito poucas possuem mecanismos de "suportes a processos de avaliação e para orientar ações de desenvolvimento profissional" (DUTRA, 2011, p. 58).

Quando não há alinhamento entre as expectativas dos gestores, organização e pessoas existe aí um conflito, pois a área de gestão de pessoas possui papel fundamental em empresas com foco em competências, pois exige um alinhamento das pessoas com a estratégia organizacional das empresas (CARBONE, 2011).

Por que então necessitamos de um modelo de gestão articulado por competências? Fischer (2012), afirma que este modelo é essencial por causa do ambiente competitivo dos tempos atuais e que os anteriores não eram adequados a esta necessidade. No entanto, para Ruas et al (2005, p. 89) a gestão de pessoas por competências ainda é vista "como um tema desafiador, dentro do subsistema de desenvolvimento humano da área de Recursos Humanos". 
Sendo assim e seguindo essa linha de mudança, é visto que surgiram várias concepções e a propensão hoje é de um entendimento integrado de gestão, envolvendo pessoas e organizações numa perspectiva estratégica. Nesse entendimento, a gestão por competências surge para organizar o processo de gerir pessoas, concordando com a visão estratégica das empresas, criando meios que possibilite o comprometimento dos indivíduos e grupos com os objetivos da organização, ao mesmo tempo que desenvolve e mantém sua vantagem competitiva diante da concorrência.

Dentro dessa visão integradora e estratégica, competência se define como o somatório de bens individuais intangíveis, que são: conhecimentos, atitudes, habilidades e experiências que resultam em um comportamento benéfico do ponto de vista organizacional, produzindo resultados satisfatórios, agregando valor econômico e social para indivíduos e empresas. Dessa forma, a competência pode ser mensurável, mostrando como os atributos conhecimentos e habilidades são aplicados diante das exigências corporativas, das diversas situações do mercado e produzindo vantagens competitivas.

\subsection{CONCEITOS}

Dentro do âmbito organizacional, o conceito de competência teve seu início quando foi vislumbrado segundo a perspectiva do indivíduo, e Segundo Chiavenato (2008), a gestão de pessoas é o conjunto integrado de atividades de especialistas e de gestores, de como irão agregar, aplicar, recompensar, desenvolver, manter e monitorar pessoas, no sentido de proporcionar competências e competitividade à organização. Partindo desse conceito, Dutra (2011) diz que atualmente o desafio maior da organização é gerir as pessoas e conseguir sustentar o comprometimento delas fazendo com que percebam que um relacionamento saudável com a organização pode lhe agregar valor.

Com base nesse desafio, é que desde os anos 80 , estudiosos interessados em uma gestão voltada para resultados, estudaram formas de repensar conceitos e ferramentas de gestão. No entanto, somente a partir do início dos anos 90 o conceito 
foi empregado em empresas brasileiras e na adaptação, em empresas multinacionais de estrutura de gestão de pessoas globais para a realidade brasileira. Apesar de bons resultados, o conceito abrangia apenas alguns aspectos de gestão de pessoas nessas empresas. No decorrer da década, o conceito de competência foi aplicado em um sistema integrado de gestão de pessoas em uma empresa do setor de telecomunicações (DUTRA, 2011).

\subsubsection{COMPETÊNCIAS: SURGIMENTO E CONCEITOS}

Se o conceito de gestão por competências se solidificou na década de 90, desde 1973 o conceito de competência vem sendo estudado por diversos teóricos do assunto, objetivando buscar "uma abordagem mais efetiva que os testes de inteligência nos processos de escolha de pessoas para as organizações". (DUTRA, 2011, p. 23).

McClelland; Boyatsis; Spencer (1973, 1982), afirmaram que nos últimos anos, a competência "tomou impulso e entrou para a pauta das discussões acadêmicas e empresariais, associado a diferentes instâncias de compreensão: em termos da pessoa (as competências do indivíduo), das organizações (as core competences) e dos países (sistemas educacionais e formação de competências).

Conforme Fleury (2010, p. 190) "competência é um saber agir responsável e reconhecido, que implica mobilizar, integrar, transferir conhecimentos, recursos, habilidades que agreguem valor econômico à organização e valor social ao indivíduo."

Sendo assim, "a agregação de valor das pessoas é, portanto, sua contribuição efetiva ao patrimônio de conhecimentos da organização, permitindo-lhe manter suas vantagens competitivas no tempo" (DUTRA, 2011, p. 24).

Parry (1996), traz o conceito de competência como sendo:

Um agrupamento de conhecimentos, habilidades e atitudes correlacionadas, que afeta parte considerável da atividade de alguém, que se relaciona com seu desempenho, que pode ser medido segundo padrões preestabelecidos, e que pode ser melhorado por meio de treinamento e desenvolvimento (p. 193). 
Não há na verdade um conceito único para o termo competências. Um ponto comum nos conceitos dos autores, é o que se chama de "Pilares das Competências", que são três: Conhecimento, Habilidade e Atitude, ou seja, o $\mathrm{CHA}^{[3]}$, como mostra a Tabela 1.

Tabela 1 - Desdobramento do CHA

\begin{tabular}{|c|c|c|}
\hline Conhecimento & Saber & Competência Técnica \\
\hline Habilidade & Saber Fazer & \\
\hline Atitude & Querer Fazer & $\begin{array}{c}\text { Competência } \\
\text { Comportamental }\end{array}$ \\
\hline
\end{tabular}

Fonte: Leme (2005, p.18)

Partindo dos conceitos acima, Fleury; Fleury (2001) indicam que a combinação de insumos como conhecimentos, habilidade e atitudes, com o desempenho comportamental do indivíduo no trabalho resultará em um desempenho profissional que gera valor tanto econômico quanto social nas organizações. Este processo é diagramado na Figura 1.

Figura 1 - Diagrama de Desempenho

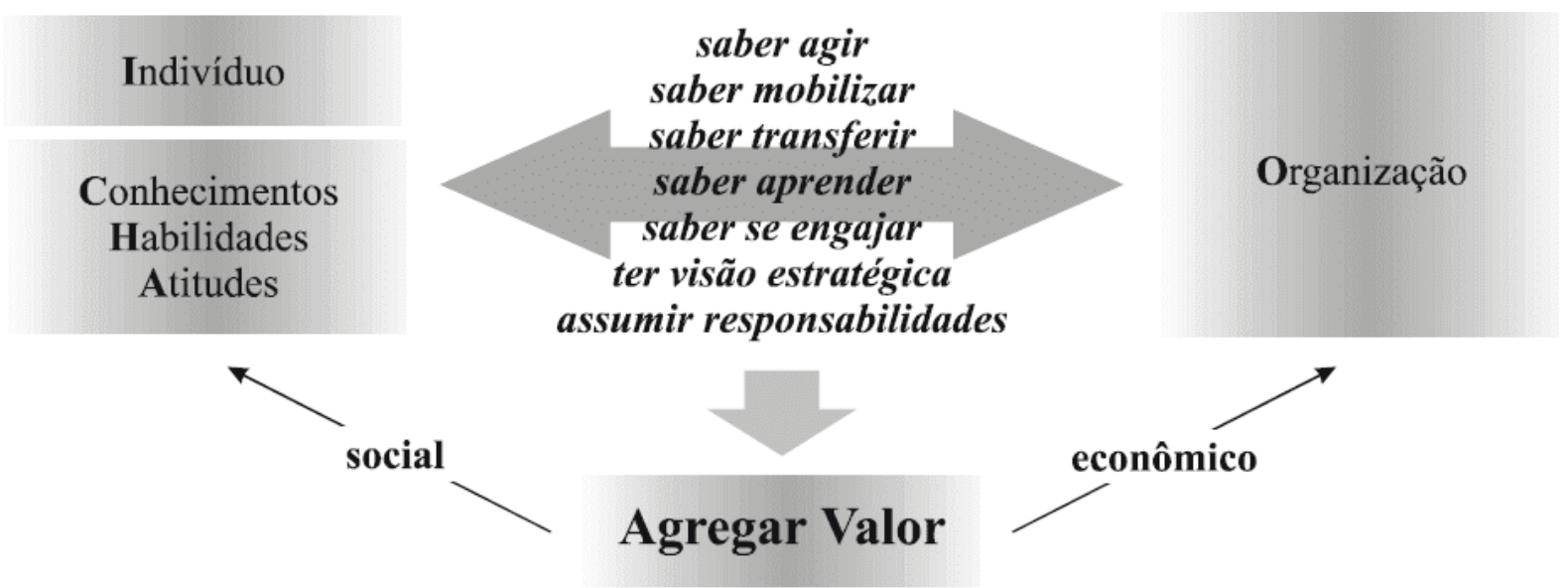

Fonte: FLEURY; FLEURY (2001, p. 57)

Para Dutra (2011) e Ruas (2005), existe uma relação íntima entre competências organizacionais e individuais. Os desenvolvimentos das competências individuais, no 
entanto, não levam necessariamente às competências organizacionais. O estabelecimento de competências individuais deve estar vinculado à reflexão sobre as competências organizacionais, já que é mútua a influência de umas e de outras. Deve haver uma perspectiva coletiva no desenvolvimento de competências, com consciência de que as competências organizacionais geram mais valor para a organização. Fleury e Fleury (2002b, p. 2), afirmam que "as competências devem agregar valor econômico para a organização e valor social para o indivíduo".

Pailloix, 1977; Braverman, 1977; Kern e Schumann, 1984, kelly e Wood, 1984; Freyssenet, 1977, dizem que não há dúvida de que a definição de competência em sua dimensão individual se confunde com uma noção que the é relativamente associada à de qualificação.

Assim, se qualificação era contextualizada num ambiente de emprego formal em que sua noção era centrada na preparação de capacidades voltadas para processos previstos ou pelo menos previsíveis em sua maioria, nos anos 90 surgiu a emergência de se ter um conceito em outro contexto no qual se destacam aceleração da concorrência, serviços baseados na lógica da atividade, trabalho informal e intermitente, além da baixa previsibilidade de negócios, e finalmente a crise nas associações sindicais trabalhistas. Nessa ótica, o conceito de competências trata de forma predominante do desenvolvimento de capacidades que podem ser posteriormente mobilizadas em situações em sua maioria pouco previsíveis. (RUAS, ANTONELLO E BOFF, 2005), ressaltam a diferença entre qualificação para o trabalho e competências, conforme demonstra o Quadro 1. 
Quadro 1 - Noções e Características dos Contextos Qualificação e Competência

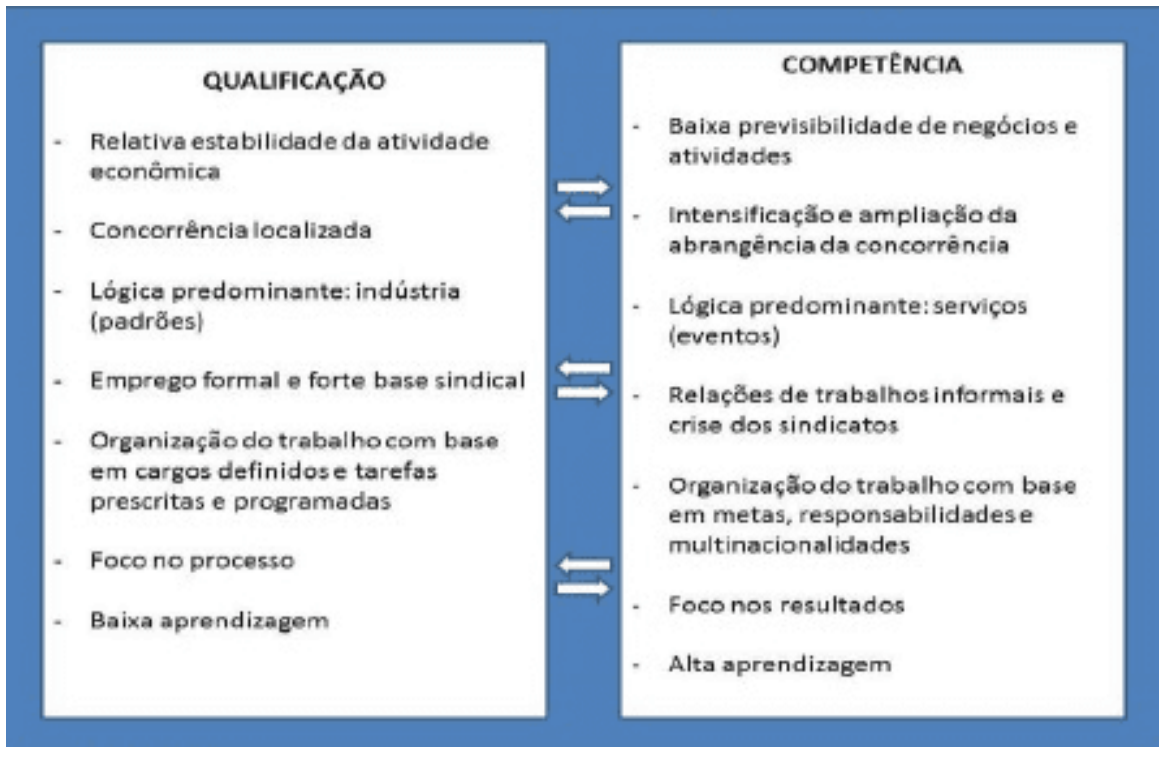

Fonte: Ruas, Antonello e Boff (2005).

Ruas, Antonello e Boff (2005) e Dutra (2011), ressaltam ainda que as competências estão em diferentes níveis organizacionais: as competências organizacionais estão no nível estratégico estando lado a lado com a missão, visão e valores da organização e dividem-se em: básicas que são as capacidades indispensáveis para a empresa administrar seu negócio; e essenciais, ligadas ao nível estratégico e fundamentais para a sobrevivência da organização. São dinâmicas, ou seja, o que é suficiente para sobrevivência da organização hoje, pode não ser com o decorrer do tempo, necessitando de ajustes constantes. Dentro dessas desenvolvem-se as competências funcionais, também coletivas e relacionadas a missão específica da área funcional, podem ter pesos diferenciados, pois relaciona-se aos cargos e salários. Um exemplo de competência funcional é a comunicação, onde a exigência de comunicação para um estagiário deve ser diferente do que para um analista.

Num entendimento similar, Furquim (2011), classifica as competências em três dimensões: a) competências individuais e/ou gerenciais: referem-se aos indivíduos. A entrega é resultado de um trabalho individual; b) competências coletivas/ou grupais: fazem referência ao coletivo. A entrega é um resultado do trabalho coletivo; e c) competências organizacionais: ligadas a estratégia da empresa e são coletivas. 
Partindo dessa nova visão do conceito de competência, Chiavenato (2008) define a gestão por competências como sendo:

...um programa sistematizado e desenvolvido no sentido de definir perfis profissionais que proporcionem maior produtividade e adequação ao negócio, identificando os pontos de excelência e os pontos de carreira, suprindo as lacunas e agregando conhecimento, tendo por base certos critérios objetivamente mensuráveis (p. 216).

Nesse modelo, o gerenciamento por competências tem uma visão das necessidades posteriores do negócio e de como as pessoas agregarão valor à organização. Para isso, a gestão por competências é uma ferramenta que caracteriza a identificação das competências essenciais, as habilidades, fornecendo recursos fundamentais para o aperfeiçoamento dessas habilidades e capacidades. Sendo assim, o que se espera são pessoas mais produtivas e comprometidas em todos os níveis da organização.

\subsection{ETAPAS BÁSICAS DENTRO DO MODELO GESTÃO POR COMPETÊNCIA}

As organizações buscam mapear as competências para ampliar o desempenho de seus colaboradores visando uma melhor competitividade no mercado, mas embora almejem isso, muitas desconhecem qual o procedimento correto a ser adotado. Qualquer empresa poderá adotar essa técnica, desde que esteja bem orientada, voltada a aceitar mudanças e rever sua própria cultura. (LEME, 2005).

Para a identificação de competências, deve ser feita uma pesquisa de ordem documental, verificando a missão, visão, valores, objetivos da organização, além dos indicadores e aspectos relativos a estratégia da empresa. Essa análise estratégica, identifica categorias para descrever o conteúdo das mensagens e elencar indicadores que permitam fazer inferências a respeito das competências relevantes. A entrevista é uma técnica muito utilizada na aplicação do mapeamento de competências, e confronta a percepção dos entrevistados com os dados apurados na análise documental. (CARBONE et al, 2006). 
Leme (2005) menciona as etapas básicas dentro do modelo de gestão por competências: mapear as competências organizacionais, identificar as competências de que uma função precisa, identificar as competências que o colaborador possui e fazer o cruzamento das informações apuradas, identificando o gap de treinamento e desenvolvimento necessário para o colaborador.

\section{SELEÇÃO POR COMPETÊNCIAS}

O processo de seleção de pessoas, inicia-se no recrutamento, quando candidatos são pré-avaliados, visando preencher uma vaga de colaborador na organização. Para que isso ocorra de forma eficaz, se deve levar em conta como ponto principal na escolha, a cultura organizacional, que deve servir de parâmetro para um recrutamento e seleção eficazes. A seleção de pessoas integra o processo de agregar pessoas e funciona logo após o recrutamento. Enquanto o recrutamento é uma atividade de atração, divulgação e de comunicação, a seleção é, ao contrário, uma atividade de escolha, de classificação e de decisão (CHIAVENATO, 1999).

"Cabem ao recrutamento e a seleção aprenderem as novas concepções do profissional requerido, a partir dos atuais paradigmas empresariais, o que vai também alterar o perfil dos recrutadores, selecionadores e do respectivo setor". (DUMONT E ROLLARD, 2007, p. 37).

\subsection{CONCEITOS E OBJETIVOS}

De acordo com Carvalho et al (2008), o recrutamento e a seleção, tem por objetivo prover a organização de competências funcionais, que irão concretizar as competências da organização. Diferente do processo de recrutamento que localiza e incentiva candidatos em potenciais a disputar vagas existentes, o subprocesso de seleção por sua vez, é um conjunto de atividades que coleta e utiliza informações dos candidatos recrutados, objetivando a escolha de quem irá preencher a vaga de emprego. A construção de um perfil de competências é importante, no entanto, não é o diferencial da seleção por competências, todo processo seletivo visa fazer um mapeamento do candidato, para entender se o mesmo possui além do perfil do cargo, 
a capacidade de se alinhar aos objetivos da organização, satisfazendo suas próprias expectativas.

Esse mapeamento refere-se ao conjunto de saberes: saber, saber fazer, saber ser. Como exemplo, podemos citar uma vaga em que a organização necessita de candidatos com capacidade de inovação contínua. Além das competências requeridas para cada cargo específico, os ocupantes da vaga deverão ser criativos, de maneira que em seus processos de trabalho produzam as inovações que sustentarão a vantagem competitiva da organização (CARVALHO et al, 2008).

$\mathrm{Na}$ fase da seleção a análise é mais criteriosa, será observado quais candidatos recrutados apresentam maiores possibilidades de adaptação e produtividade diante da cultura e clima organizacional e das estratégias da organização.

Rabáglio (2001), informa que a seleção por competências foi idealizada para que os gestores pudessem formar equipes de trabalho de forma consistente, que tivessem foco e fossem objetivos. Segundo o autor, este tipo de seleção tem uma aplicabilidade no mapeamento do perfil, pois é através dela que será possível identificar se o candidato tem ou não as competências necessárias para realizar a atividade. Além disso, esta seleção usa como ferramentas, a entrevista comportamental e os jogos, mas nunca deixando de focar as competências dos candidatos.

Balerini (2003), por sua vez afirma que o desafio deste tipo de seleção é fazer com que a organização tenha previamente definidos quais tipos de competências são necessárias para cada função a ser desempenhada na empresa e após uma seleção tradicional onde foram realizadas a avaliação das características pessoais e profissionais, os avaliadores, entram com o método da seleção por competências, onde são escolhidas no máximo dez competências a serem avaliadas e com esta base, aplicam o testes nos candidatos finalistas.

Rabáglio (2001),destaca que as vantagens deste tipo de seleção são: a objetividade com que é realizada a seleção, uma forte consistência em identificar nos candidatos as competências necessárias para o preenchimento da vaga, conseguir prever de 
certa forma o desempenho futuro do candidato, maior acerto na adequação do profissional com a função e consequentemente com a organização, o que por sua vez leva a uma baixa rotatividade de profissionais, além de aumentar a credibilidade para com o cliente interno da organização.

\subsection{ENTREVISTA COMPORTAMENTAL E JOGOS}

A entrevista é o primeiro contato do indivíduo com a organização. É a partir dela que o gestor poderá avaliar melhor o candidato. O responsável pela seleção, deverá fornecer ao gestor todas as informações colhidas anteriormente nos subsistemas de recrutamento e seleção.

Carvalho et al (2008) lembra que o gestor responsável pela seleção, deverá levar em conta os sinalizadores de competências que são: descrição do cargo, principais desafios do cargo, maiores erros cometidos no cargo, projetos a serem desenvolvidos pelo ocupante do cargo, características dos principais clientes e fornecedores internos, cultura da equipe de trabalho, estilo de liderança do superior e cultura da empresa.

Além da entrevista, os jogos são aliados muito importantes na seleção por competências, e segundo Huizinga (1993) o jogo é:

uma atividade ou ocupação voluntária, exercida dentro de certos e determinados limites de tempo e espaço, segundo regras livremente consentidas, mas absolutamente obrigatórias, dotado de um fim em si mesmo, acompanhado de um sentimento de tensão e alegria e de uma consciência de ser diferente da vida cotidiana (p. 33).

Huizinga (1993), diz ainda que através dos jogos, as competências dos candidatos podem ser observadas, estando dentre estas: a motivação, a liderança, a iniciativa, a criatividade, a inovação, a ética e a comunicação.

Os jogos utilizados são diferentes e cada um permite explorar possibilidades diferentes, segundo a necessidade do processo que está em questão. Por exemplo, há jogos em que os participantes podem assumir papéis, revelando sempre um 
posicionamento por parte do candidato e revelando assim, características que as vezes tem a tendência de mascarar, quer seja por inibição, quer seja por receio de perder a oportunidade de trabalho (GRAMIGNIA, 1993).

\subsection{AVALIAÇÃO DO CANDIDATO}

Depois de se ater sobre o que foi dito por todos os autores acima, determinasse que a seleção por competências, deve ser considerada como um método que tem em sua essência a busca pelas experiências que de fato foram vividas pelos candidatos e que possam oferecer a quem está entrevistando, subsídios para que possa entender e até mesmo prever comportamentos futuros dos candidatos.

Segundo Rabáglio (2001), este tipo de metodologia pode ser utilizada por qualquer pessoa que seja treinada previamente, e a tendência é que a avaliação do candidato seja feita por esta metodologia, não mais pelo $\mathrm{RH}$ e sim pelos próprios gestores, pois são justamente estes, que tem conhecimento do perfil adequado que deve ter o candidato para preencher os requisitos do cargo, além disso, este tipo de avaliação terá a tendência de aproximar de imediato o gestor e o futuro colaborador.

\section{4. ÉTICA NO PROCESSO SELETIVO}

Segundo Monteiro e Cols (2005) a ética deve fazer parte em todas as etapas de um processo seletivo, mas infelizmente, os autores sugerem que nem sempre é assim, pois existem profissionais que buscam utilizar meios questionáveis para realizar o processo seletivo.

Sobre isso, James Burke (1987), afirma:

Acredito que há uma necessidade profunda e intensamente humana de confiança, honestidade, integridade e conduta ética com as pessoas com quem criamos importantes relacionamentos. Além do mais, acredito que esse imperativo moral deve motivar empresas a se esforçarem para satisfazer essa necessidade que diz respeito a todos os seus constituintes, clientes empregados, enfim todos os que dela dependem. $\mathrm{E}$, finalmente, acredito que as empresas que são mais consistentemente éticas em sua conduta serão, em média, mais bem-sucedidas (p. 11-12). 
Ainda, de acordo com Oyamada (2005), os processos de seleção devem ser sempre baseados na ética, para que as etapas de uma seleção sejam harmoniosas, funcionem como planejado e não prejudiquem o candidato que ali está realizando o processo. O autor afirma também, que este cuidado com a ética é essencial, porque todo processo seletivo cria expectativas e envolve de forma direta a vida e o futuro daqueles que estão participando da seleção, portanto, devem sempre ser tratados com o mais profundo respeito, não somente durante o processo, mas também depois.

\section{CONSIDERAÇÕES FINAIS}

O presente estudo teve como como objetivo, identificar a relação da seleção por competências na gestão das organizações o que por sua vez determinou como objetivos específicos: identificar a gestão por competências; explicar o conceito de competência e identificar a relevância das competências na seleção de pessoas.

Como resposta ao problema de pesquisa que investigou a relação entre a seleção por competências e a influência do mesmo na gestão das organizações, a bibliografia estudada, mostrou que no meio empresarial, o que outrora não era visto como um patrimônio, atualmente o é, pois os conhecimentos adquiridos pelos colaboradores são fundamentais para o sucesso e continuidade da empresa, e por isso o processo de seleção tem sido mais qualificado e com foco nas competências, porque a perpetuação do colaborador é vital para todos os processos de gestão, principalmente em uma gestão por competências.

Não é mais tido como espantoso, o fato de se ter em uma gestão uma seleção por competência, mesmo no Brasil. Muito embora não seja uma unanimidade dentre as seleções realizadas na maioria das empresas, este tipo de seleção já tem alcançado níveis bons de aceitação e embora ainda se apresente uma séria de indefinições acerca da gestão por competências, ela vem sendo utilizada mesmo que muitas vezes ainda não de forma totalmente adequada. Mas o que ficou estabelecido de forma clara é que as competências individuais dos colaboradores existem e elas devem ser vinculadas as organizações, para que ambos obtenham sucesso, tanto na execução quanto na absorção das atividades realizadas, o que por sua vez gera transformações, 
bem como a aquisição de conhecimentos organizacionais, habilidades e atitudes que serão utilizadas e também perpetuadas dentro do processo organizacional.

Olhando dentro desta ótica, podemos então deixar evidente que a seleção de pessoas é vital dentro de uma organização, e que a seleção por competências somente agrega benefícios na seleção do que representa hoje em dia o principal ativo de uma organização, ou seja, os colaboradores. Por outro lado, se houverem falhas neste processo de seleção haverá prejuízos para a organização, sendo assim, mais uma vez a bibliografia estudada indica que realizar a seleção da pessoa certa para o cargo certo, evidencia uma gestão por competências eficaz e por consequência, demonstra que os gestores estão agindo de forma correta, para com a gestão da empresa.

De fato, a seleção por competências possibilita ao gestor identificar a pessoa correta para cada função, seguindo as suas competências, e isto faz com que outras questões sejam colocadas em prática de forma mais natural, como por exemplo, políticas de desenvolvimento de pessoas e planos de carreiras, o que vem a causar a redução de rotatividades de colaboradores, uma vez que os mesmos estão obtendo satisfação pessoal, e tem um futuro a vislumbrar, além de desempenhar suas atividades de forma correta, devido a identificação de suas competências para a função, no momento da seleção.

Os métodos utilizados na seleção por competências são vários, mas neste estudo foram priorizados, a entrevista comportamental e os jogos, já que estes dois são os mais utilizados no processo de seleção por competências.

Portanto, podemos concluir neste estudo que a seleção por competências é vital para tornar o processo de seleção mais fidedigno, evitando falhas que muitas vezes são evidenciadas em outros tipos de processos de seleção, de fato, a seleção por competências tem levantado dentro das organizações a questão de se escolher o candidato certo para ocupar a vaga certa, pois este tipo de seleção avalia de forma muito precisa as competências individuais do candidato. 
O que mais ainda podemos destacar é que a análise da seleção por competências, pode e deve ser estudada em diversos contextos, haja visto que ainda é um processo a ser explorado e pode ser realizado por meio de outras maneiras que não somente a pesquisa bibliográfica, pois se a exploração vier por outros meios, mais conclusivos poderão ser os resultados acerca do método de seleção por competências.

Diante do exposto, fica aqui o incentivo para que mais pesquisadores se aprofundem no assunto e desenvolvam estudos futuros no campo da seleção por competências, realizando pesquisas de cunho qualitativo, dentro de empresas que já são utilizadoras deste tipo de processo, podendo assim então, entender e contribuir com conhecimento dentro desta temática, objetivando alcançar todos aqueles que querem ter conhecimento do papel de uma seleção por competências e a sua colaboração dentro da gestão por competências nas organizações.

\section{REFERÊNCIAS}

AGUILAR, Francis Joseph. Ética nas Empresas: Maximizando Resultados Através de uma Conduta Ética nos Negócios. Tradução Ruy Jungmann. Rio de Janeiro: J. Zahar, 1996.

ARAUJO, lara Guerra. A Competência na Seleção de Pessoas. Dissertação de Mestrado, UNB, Brasília, 2011. Disponível em: <http://docplayer.com.br>. Acesso em: 19 ago. 2016.

BALERINI, Cristina. Seleção baseada em competências e habilidades. 2003. Disponível em: <http://www.catho.com.br/estilorh>. Acesso em: 20 ago. 2016.

BELFOR Rhecyelle Mota; FRANCO, E. F. M. S; TADEUCCI, Marilsa S. R. Gestão por Competências: um novo modelo de gerenciamento. 2012. Pesquisa de Mestrado. Disponível em: <http://www.unisulma.edu.br>. Acesso em: 27 ago. 2016.

BISPO, Patricia. Qual o melhor método no processo de seleção. 2003. Disponível em: <http://www.rh.com.br>. Acesso em: 18 set. 2016. 
BISPO, Patricia. Utilizando a seleção por competências. 2003. Disponível em: $<$ http://www.rh.com.br>. Acesso em: 20 set. 2016.

CARBONE, Pedro Paulo; BRANDÃO, Hugo. P; LEITE, João B.D; VILHENA, Rosa M.P. Gestão por competências e gestão do Conhecimento. 2 ed. Rio de Janeiro: Editora FGV, 2006.

CARVALHO, leda Maria Vechioni; PASSOS, Antonio Eugênio Valverdi Mariani; SARAIVA, Suzana Barros Corrêa. Recrutamento e Seleção por Competências. 1.ed. Rio de Janeiro: FGV. 2008. E-Book. ISBN 978-85-225-1227-0. Disponível em: $<$ https://ler.amazon.com.br>. Acesso em: 25 ago. 2016.

CASA NOVA, Camila Correa. Artigo Gestão por Competências Os desafios e as possibilidades da Seleção por competência. Dissertação de Mestrado, UFRGS, Porto Alegre, 2013. Disponível em: <https://www.lume.ufrgs.br>. Acesso em: 12 ago. 2016.

CHIAVENATO, Idalberto. Administração nos novos tempos. 2. ed. Rio de Janeiro: Campus, 1999.

CHIAVENATO, Idalberto. Gestão de Pessoas: o novo papel dos recursos humanos nas organizações. 3. ed. Rio de Janeiro: Elsevier, 2008.

DUTRA, Joel Souza. Competências: Conceitos e Instrumentos para a Gestão de Pessoas na Empresa Moderna. 1르 edição. São Paulo: Atlas, 2011.

FLEURY, A.; FLEURY, M. T. L. Estratégias empresariais e formação de competências: um quebra cabeça caleidoscópico da indústria brasileira. 2001. 2. ed. São Paulo: Atlas.

FLEURY, M. T. L.; OLIVEIRA JUNIOR, M. M; Gestão Estratégica do Conhecimento: Integrando Aprendizagem, Conhecimento e Competências. São Paulo: Atlas. 2010.

GRAMIGNIA, M. R. M. Jogos de empresa. 1993. São Paulo: Makron Books Editora. 
HUIZINGA, J. Homo Ludens: o jogo como elemento da cultura. 1993. São Paulo: Ed. Perspectiva.

KAIBER Solange, Competência - do conceito CHA para CHAVE. 2011. Disponível em: <http://sucesso-organizacional.blogspot.com.br>. Acesso em: 22 ago. 2016.

LACOMBE, Francisco José Masset. Recursos Humanos: Princípios e Tendências. $2^{2}$ edição. São Paulo: Saraiva. 2011.

LEME, Rogério. Aplicação Prática de Gestão de Pessoas por Competências: mapeamento, treinamento, seleção, avaliação e mensuração de resultados de treinamentos. Rio de Janeiro: Qualitymark, 2005. Greice de Bem Noro; Maylson Pauletto; Bruna Fialho. Disponível em: http://www.aedb.br/seget/arquivos/artigos11/731439.pdf. Acesso em: 19 set. 2016.

MARTINS, Vitor W. Batista; NEVES, Renato Martins; MACEDO Alcebíades Negrão. Análise do desenvolvimento de competências gerenciais na construção civil através do modelo da Aprendizagem Baseada em Problemas adaptados ao contexto Organizacional. 2014. Disponível em: <http://www.scielo.br>. Acesso em: 31 ago. 2016.

MONTEIRO, J. K. e COLS. Valores, Ética e Julgamento Moral: um estudo exploratório em empresas familiares. 2005. Revista Psicologia Reflexão e Crítica, 18 (2), pp 237 - 246. Porto Alegre: UFRGS.

MUSSAK, Eugênio. A nova competência: de que adianta produzir sem sustentabilidade, competir sem ética e conquistar sem moral? 2009. Disponível em: $<$ http://planetasustentavel.abril.com.br>. Acesso em: 22 ago. 2016.

OLIVEIRA, Márcia Regina de; SANTOS, Isabel Cristina dos; LOURENÇÃO, Paulo Tadeu de Mello. Avaliação por competências em ambientes de alta tecnologia. In: CHAMON, Edna Maria Querido de Oliveira (Org). Gestão Integrada de organizações. Rio de Janeiro: Brasport, 2008. 
OYAMADA, Gino, M. Recrutamento com ética. São Paulo: Gazeta Mercantil, 2005.

RABAGLIO, M. O. Seleção por Competências. 2007. Disponível em: <http://guiarh.com.br/04htm>. Acesso em: 16 out. 2016.

RUAS, R.L; ANTONELLO, C.S; BOFF, L.H. Os Novos Horizontes da Gestão: Aprendizagem Organizacional e Competências. $2^{\mathrm{a}}$ edição. Porto Alegre: Bookmam, 2005.

\section{APÊNDICE - REFERÊNCIAS DE NOTA DE RODAPÉ}

3. Kaiber (2011); e Mussak (2009), afirmam que no cenário moderno de constantes mudanças, pesquisadores estudam um novo conceito para Competência, incluindo duas relevantes letras, o conceito CHA torna-se CHAVE, incluindo os valores que baseiam a vida do indivíduo e sua preocupação com a sustentabilidade e o Entorno que é uma responsabilidade da organização de fornecer um ambiente com condições e estratégias, prezando pelo colaborador, disponibilizando condições e recursos, fazendo com que ele exerça sua competência. Esse elemento está mais fora do que dentro do indivíduo. Lembrando que mesmo estando latentes, a maioria dos autores inclui esses valores em seus conceitos.

Enviado: Setembro, 2019.

Aprovado: Outubro, 2019. 